\title{
Short Note \\ Quantifying the Media Bias in Intensity Surveys: Lessons from the 2001 Bhuj, India, Earthquake
}

\author{
by Susan E. Hough and Prabhas Pande
}

\begin{abstract}
Many seismologists have looked at the 26 January 2001 Bhuj earthquake as a key modern calibration event that could be used to improve estimates of magnitudes of large historic mainshocks in stable continental regions. Since no instrumental data are available for important historic events such as the 1819 Allah Bund, India, and the 1811-1812 New Madrid, central U.S. mainshocks, calibration hinges on comparisons of the macroseismic effects of these earthquakes with those of comparable modern earthquakes for which a reliable, instrumentally determined moment magnitude is available. However, although such a comparison is conceptually straightforward, in practice it is complicated by potentially significant inconsistencies in methods used to quantify macroseismic effects in different regions and/ or times. For the Bhuj earthquake, extensive intensity data sets have been compiled and published from both media accounts and detailed direct surveys. Comparing the two provides a quantification of the previously suspected media bias, whereby earthquake effects can be exaggerated in media accounts. This bias is a strong function of intensity level, with substantial bias at the highest shaking levels and significantly less bias at low intensities. Because only sparse documentary data are in general available for older historic earthquakes, the results of this study suggest that their inferred intensity distributions might be similarly biased. We further use the surveybased intensity values to develop a new relationship between intensities and ground motions.
\end{abstract}

\section{Introduction}

The $M 7.6$ Bhuj earthquake occurred in the state of Gujarat, India at 03:16 GMT (8:46:42.9 am, local time) on 26 January 2001 (Bendick et al., 2001). The event struck within the Kachchh peninsula near India's western coast and was felt across much of the Indian subcontinent. Official government figures placed the death toll at just over 13,800 and the number of injured at 166,000. Eyewitnesses reported that approximately one building in ten remained standing in Bhuj and Anjar, the closest large cities to the epicenter. The mainshock was well recorded at teleseismic distances: these data have been used to develop a kinematic rupture model and to obtain a well-constrained moment magnitude, $M_{\mathrm{W}}$, value of 7.6 (Antolik and Dreger, 2003). Near-field and regional instrumental recordings of the Bhuj earthquake are scarce, however, (e.g., Singh et al., 2003; Iyengar and Kanth, 2006). The assessment of macroseismic effects was therefore of paramount importance for understanding the distribution of damage and shaking as well as to provide a basis for comparison with important historic earthquakes.

The macroseismic effects of the Bhuj earthquake have now been quantified by using two independent methods. Intensity values have been determined from (1) extensive news articles written in the early aftermath of the Bhuj earthquake, published in both conventional newspapers and on the Web (Hough et al., 2002, hereinafter MEDIA02), and (2) from extensive, direct surveys and interviews conducted by the Geological Survey of India (Pande, 2003, hereinafter, GSI03). The former study used the modified Mercalli intensity (MMI) scale (e.g., Stover and Coffman, 1993) and the latter assigned intensities by using the Medvedev-SponheuerKarnik (MSK) intensity scale (e.g., Grunthal, 1998). The two are, in general, regarded as equivalent or nearly so: the latter represents a more recent modification that primarily provides greater clarity regarding the interpretation of damage to different types of structures, in particular, building types commonly found throughout Europe (Grunthal, 1998).

The intensity assignments by both MEDIA02 and GSI03 were made with careful consideration of building types and vulnerabilities. The earliest intensity scales were developed with a recognition of the importance of taking these factors 
into account. Later formulations of scales, such as MSK, have increasingly formalized the consideration of building vulnerability. Applied correctly, modern MMI and MSK assignments should reflect ground motions, not the degree of vulnerability of local building stock (e.g., Ambraseys and Melville, 1982).

Attempts to characterize the distribution of macroseismic effects date back at least as far as Robert Mallet's pioneering efforts to map the effects of the 1857 Neapolitan earthquake (Mallet, 1862). Although many heroic efforts were made to directly assess the macroseismic effects of other nineteenth century earthquakes (e.g., Oldham, 1899), intensity distributions for historic earthquakes are determined in general from later interpretations of documentary accounts. By their nature, such accounts tend to focus on dramatic rather than representative effects. Other factors, in particular, inherent human subjectivity, can clearly bias any intensity study. Some early intensity evaluations have arguably overemphasized subjective and/or especially dramatic effects (e.g., Nuttli, 1973; Strand, 1980), leading to inflated magnitude values (e.g., Hough et al., 2000; Hough and Elliot, 2004). By its nature, an intensity scale demands a consideration of representative rather than extreme effects (e.g., Ambraseys and Melville, 1982); an approach formalized in algorithms developed for the Community Internet Intensity Map project (Wald et al., 1999). However, when intensity evaluations rely by necessity on documentary accounts, the question remains as to whether available accounts provide a good characterization of representative effects.

The approaches used to assign intensities for MEDIA02 and GSI03 were consistent: in both studies an attempt was made to assign representative intensities based on the available accounts and observations of damage and other effects. The careful consideration of building vulnerability also lessens, although does not entirely obviate, the possibility that the results of either study are biased by a failure to account properly for the nature of local structures. The key difference between the studies is that the media accounts provided only a selective snapshot of the macroseismic effects, whereas the direct surveys provided a far more comprehensive view. In effect, the media-based approach arguably provides a modern analog for macroseismic investigations of historical earthquakes for which only documentary data are available. (For modern earthquakes - and relatively more recent historical events - one also often has considerable additional photographic information available. Although here again the question arises: are the snapshots representative?) The availability of two extensive, independent macroseismic assessments of the Bhuj earthquake further provides an opportunity to explore and quantify biases associated with the determination of intensities from documentary data. Ideally one would like to compare such results for a large number of earthquakes; unfortunately, such opportunities are rare, especially for large intraplate events.

\section{Comparison of Results}

Intensity distributions cannot be compared without carefully considering the methods and assumptions used to assess intensities. For example, the treatment of secondary effects such as landslides and liquefaction can vary considerably between not only different intensity scales, but also between different assessments using a given scale. The MSK scale differs from the MMI scale in that the former explicitly cautions against the assignment of intensities based solely on effects of nature, such as liquefaction, rock slides, etc. As originally formulated, the MMI scale can be used to assign intensities based on such observations alone. Recent results have confirmed that effects such as liquefaction can be poor indicators of overall shaking levels (e.g., Musson, 1998; Ambraseys and Douglas, 2004; Hough and Elliott, 2004). Although this might appear self-evident to anyone familiar with the gross nature of earthquake effects, some early studies have relied heavily or exclusively on secondary effects to assign intensities where no other information is available (e.g., Nuttli, 1973; Strand, 1980). Recently, some researchers have adopted the MSK approach of not assigning MMI values based on such effects (e.g., Bakun and Hopper, 2004). Although sensible in many respects, this has the unfortunate result that the MMI scale is essentially redefined "on the fly"; thus, MMI data sets from different earthquakes cannot be directly compared without a careful consideration of the approach used in each individual study.

Hough et al. (2002) assigned intensity values according to the strict criteria of the MMI scale, in part, to facilitate comparisons between their values and those determined for other earthquakes. Accordingly, some sites were given MMI values of VII-VIII based on accounts of liquefaction alone, although it was recognized that these might not reflect the overall level of ground motion. Their final data set includes MMI values for nearly 200 sites throughout the Indian subcontinent, with the highest concentration of values within $300 \mathrm{~km}$ of Bhuj. For the purposes of comparison with GSI03, 21 intensity values based solely on liquefaction will be excluded from the data set.

The GSI survey was carried out between 28 January and 16 February 2001, and included approximately 300 localities spread over an area of 1.2 million square km (Pande, 2003), yielding MSK values at 299 locations throughout India. This survey did not extend to neighboring countries where the earthquake was felt, which complicates comparisons with MEDIA02. If one is seeking to compare the results of the two approaches, one clearly cannot supplement the GSI results with intensity values that were not determined consistently. However, for 15 locations in Pakistan, Nepal, Bangladesh, and Sri Lanka, available accounts allow intensities to be inferred with some measure of confidence. These are almost all sites where the earthquake was reported as lightly felt, or where definitive not-felt reports are available (Table 1). We include these points for illustrational purposes only. 
Table 1

Additional MMI Results for 15 Locations in Neighboring Countries

\begin{tabular}{lcclc}
\hline \multicolumn{1}{c}{ Location } & Longitude & Latitude & \multicolumn{1}{c}{ Effects } & MSK \\
\hline Ghotki, Pakistan & 69.33 & 28.00 & "brief spell of earthquake" & 3 \\
Jacobabad, Pakistan & 68.43 & 28.28 & "brief spell of earthquake" & 3 \\
Karachi, Pakistan & 67.04 & 24.51 & doors swung, buildings cracked & 5 \\
Kathmandu, Nepal & 85.28 & 27.73 & hanging objects swung & 3 \\
Kotri, Pakistan & 68.22 & 25.22 & strong shaking & 4 \\
Lahore, Pakistan & 74.40 & 31.54 & "severe" shaking & 4 \\
Larkana, Pakistan & 68.15 & 27.33 & "brief spell of earthquake" & 3 \\
Peshawar, Pakistan & 71.86 & 33.28 & "felt" & 3 \\
Quetta, Pakistan & 67.02 & 30.31 & "felt" & 3 \\
Rohri, Pakistan & 68.57 & 27.41 & "brief spell of earthquake" & 3 \\
Shrikarpur, Pakistan & 68.64 & 27.97 & "brief spell of earthquake" & 3 \\
Sukkur, Pakistan & 68.85 & 27.69 & "brief spell of earthquake" & 3 \\
West Bangladesh & 90.0 & 24.0 & felt & 3 \\
East Bangladesh & 89.0 & 24.0 & not felt & 1 \\
Sri Lanka & 81.0 & 8.0 & not felt & 1 \\
\hline
\end{tabular}

The modified MEDIA02 and GSI03 are presented in graphical form in Figures 1 and 2.

The qualitative comparison illustrated in Figures 1 and 2 suggests that the media- and survey-based intensity values are generally consistent. To explore the comparison in more depth, we construct histograms of the number of observations of each intensity level as a function of epicentral distance (Fig. 3). Each distinct location is represented by only a single average intensity value: typically there is one value from a given city or village, although for a few larger cities (e.g., Mumbai), intensity values were available for different locations within the city. To compare the results further one can calculate the average distance at which each intensity level is assigned: Rm and Rs for the media- and surveybased values, respectively. The fractional media bias, MBS, is then quantified simply as

$$
\mathrm{MBS}=(R m-R s) / R s .
$$

Figure 4 shows MBS calculated both with and without the media-based intensity values based solely on liquefaction. MBS is calculated using only those points at which intensities were assigned by GSI, not those shown in Figure 2 from outside India.

Figure 4 confirms the tendency for liquefaction-based assignments to overestimate true shaking levels. Although the degree of overestimation depends on the number of such values relative to the number of high-intensity values constrained by damage observations, Figure 4 reveals that the bias can be significant for earthquakes that generate widespread liquefaction. Isoseismal areas for intensities VIII and IX are reduced by as much as $75 \%$ if liquefaction-based assignments are excluded.

Even with liquefaction-based intensities excluded, Figure 4 reveals a strong increase in MBS with intensity level. Media-based isoseismal areas for MMI VII-IX are about $50 \%$ higher than survey-based isoseismal areas. These are shaking levels at which moderate-to-severe damage occurs; the results thus provide quantification of the extent to which media accounts overemphasize locally anomalous damage.

Figure 4 reveals that, although MBS is $23 \%$ for MMI V, this intensity level is in fact observed at a comparable distribution of distances in the two studies. The average value of MBS is essentially biased by two outliers at large distances. Intensity V is a level at which, typically, no structural damage occurs, but in general this level is assigned based on definite indicators: small objects overturned, doors swung, and pendulum clocks stopped or interrupted. The consistency of assignments of this level suggests that such observations do not lend themselves to overinterpretation. The low value of MBS for MMI III suggests that "lightly felt" is essentially a binary observation, and therefore perhaps difficult to misinterpret. (Including intensity III assignments from outside India actually increases MBS slightly, from $-11 \%$ to $-6 \%$ ). The isoseismal areas for low-shaking levels are thus not likely to be greatly exaggerated, although some care clearly is required to not allow an MMI II-III contour to be defined by unusual isolated points.

\section{Ground Motions}

The Bhuj mainshock was not well recorded at local or regional distances, yet some direct, quantitative observations of ground motions are available. Chandra et al. (2002) determined peak ground accelerations (PGA) from 13 structural response recorders at distances of 30-288 km; these instruments sample hard rock and alluvial site conditions. Traditional broadband data were also recorded at epicentral distances of 565-1794 km on 16 regional stations throughout India (Singh et al., 2003). Using the MMI-PGA relation of Wald et al. (1999) to convert GSI03 intensity values, we obtain values that are higher by nearly a full order of magnitude than recorded values (Fig. 5a). Even allowing for the possibility that intensity values might be systematically 
(a)

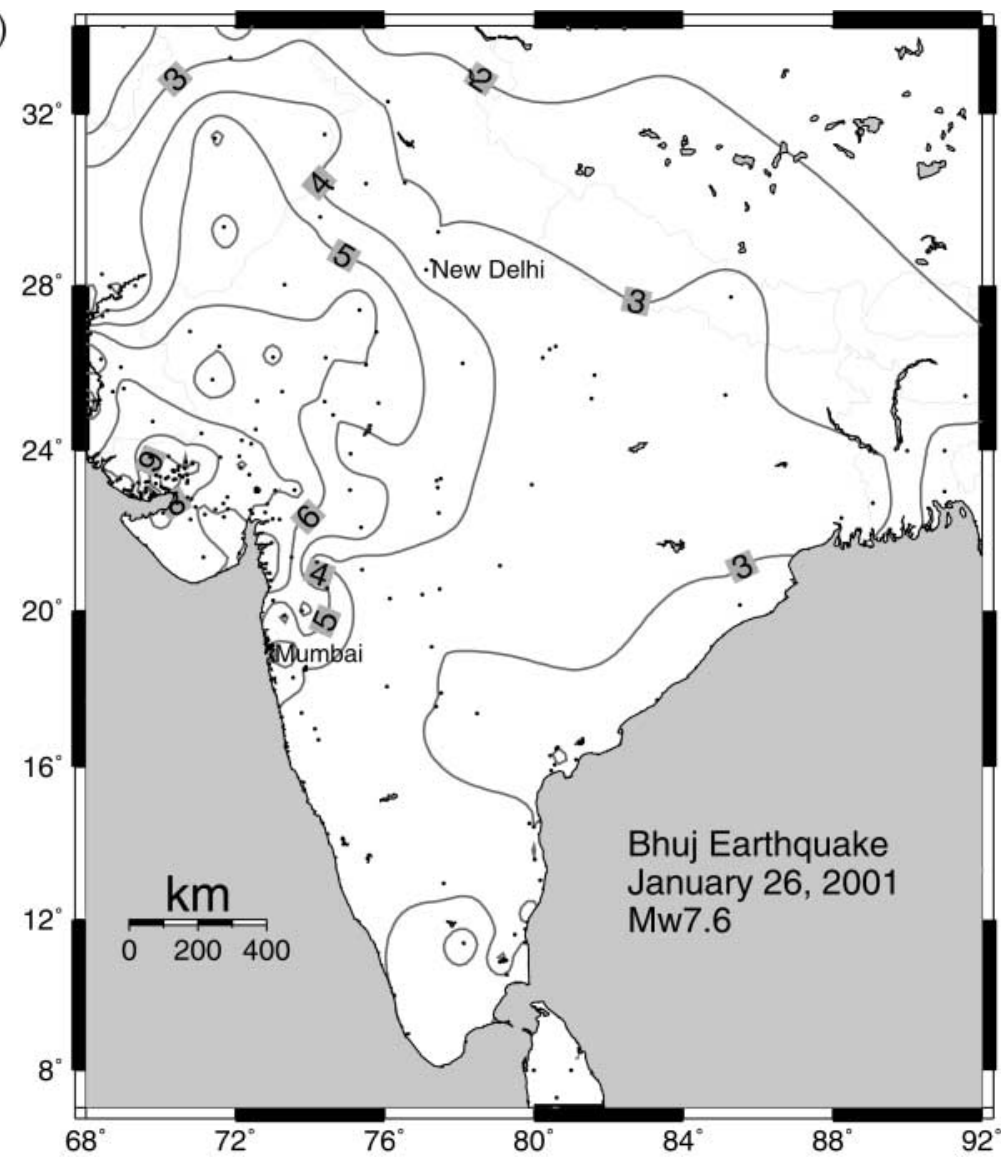

Figure 1. (a) Inferred MMI values (MEDIA02) for the Bhuj earthquake determined by Hough et al. (2002). Contouring is done by using the generic mapping tools (GMT) utility grdcontour (Wessel and Smith, 1991). (b)

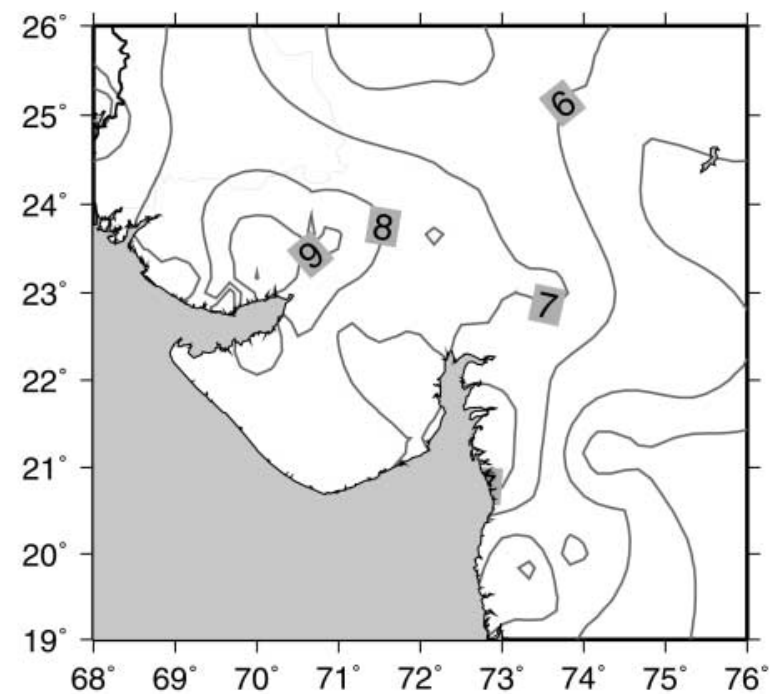

Figure 1. (continued) (b) Close-up view of the near-field region.

biased by site response, the discrepancy suggests that the relation of Wald et al. (1999) is not appropriate for the Bhuj earthquake.

Atkinson and Sonley (2000) developed a relationship between intensity and ground-motion parameters that in- cludes a dependence on both earthquake magnitude and distance, $D$. For $M_{\mathrm{W}}$ 7.6, their relationship for PGA yields

$\log (\mathrm{PGA})=(\mathrm{MMI}-2.8 \log (D)+10.71) / 6.08$.

This relationship was constrained by data from 29 California earthquakes with magnitudes of 4.9 to 7.4 recorded at distances up to $300 \mathrm{~km}$. Using equation (2) to convert GSI03 intensity values to PGA thus involves substantial extrapolation beyond the distance range for which the equation is valid. As illustrated in Figure 5b, the resulting PGA values agree well with observations over the distance range 0 $300 \mathrm{~km}$, but, not surprisingly, the agreement is not as good at regional distances. The mismatch at large distances may reflect not only extrapolation issues but also differences in wave propagation in California versus peninsular India. For example, it is possible that ground motions with comparable PGA values will be felt more strongly in intraplate than interplate regions because of the higher-frequency nature of intraplate ground motions.

The Bhuj data cannot be used to invert for a MMI-PGA relationship because the observed PGA values are so limited. One can, however, adjust a simple MMI-PGA relationship to better fit observed PGA values (Fig. 6). Estimated PGA values using this relationship are shown in Figure 5c. The new assignments in general preserve the linear trend be- 
(a)

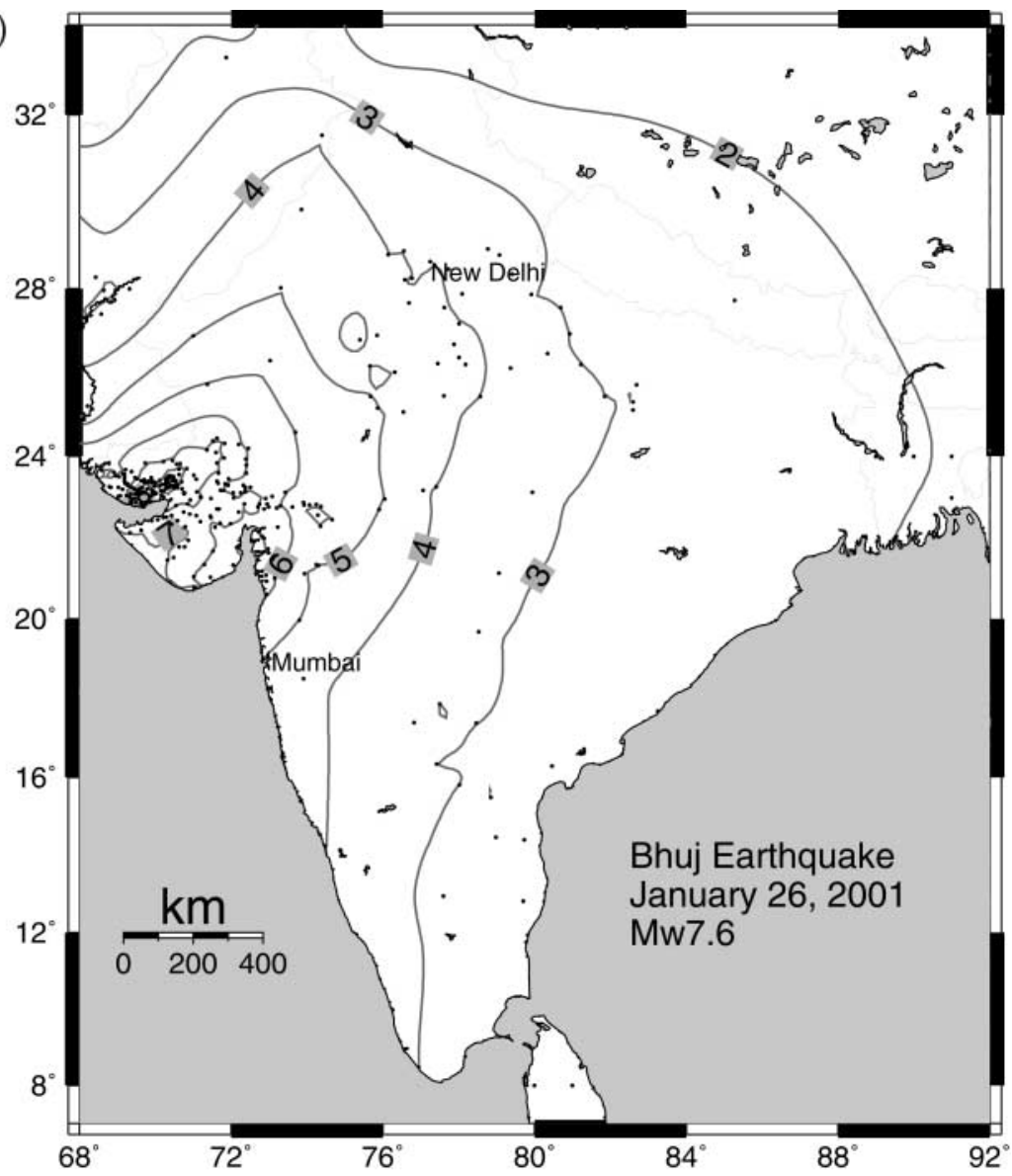

Figure 2. (a) Inferred MSK values (GSI03) for the Bhuj earthquake determined by Pande (2003). Contouring is done by using the GMT utility grdcontour (Wessel and Smith, 1991). (b)

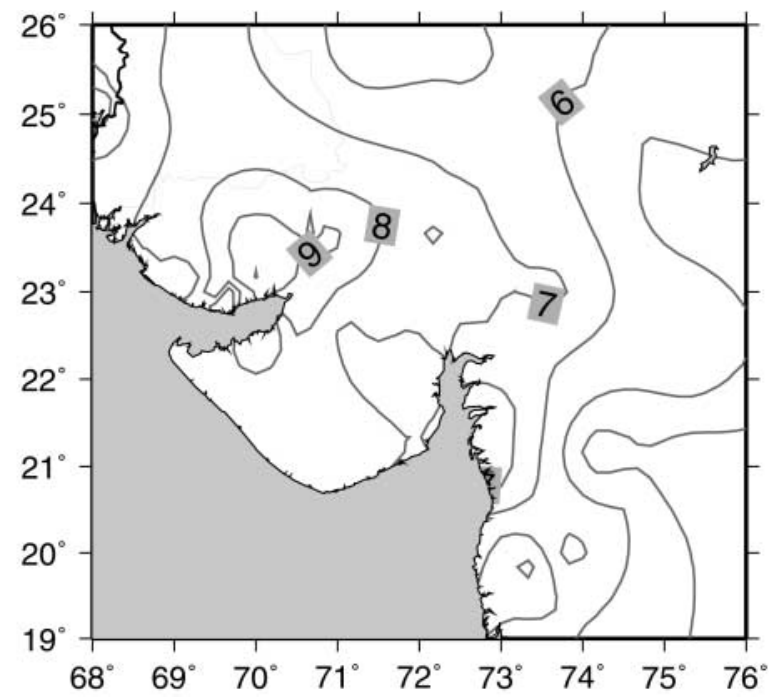

Figure 2. (continued) (b) Close-up view of the near-field region.

tween intensity and $\log$ (PGA) that previous studies have inferred. We also adjust the relationship so that the lowest perceptible ground motions correspond to a PGA of $0.1 \% \mathrm{~g}$, as previous studies have suggested (see Trifunac and Brady, 1975) and as the broadband data in fact suggest. At distances of $0-400 \mathrm{~km}$ the predicted and observed PGA values are consistent. At distances of 700-2000 km predicted values are in general somewhat higher than those observed; this is consistent with our expectation that, although the broadband instruments in general sample hard-rock site conditions, at large distances the earthquake was preferentially felt at sediment sites.

At intensity levels II-IV ground motions do not cause damage: these levels are assigned primarily based on a human perception of shaking severity, for example, whether shaking is felt by a few, some, or most people. We suggest that, in addition to site response, duration may be the key difference between Bhuj ground motions felt at regional distances and the ground motions that constrained the Wald et al. (1999) results. As discussed by Hanks and Johnston (1992), large intraplate earthquakes will generate especially prolonged $L g$ wave trains at regional distances. Clearly, if shaking is at the edge of human perceptibility, it is more likely to be noticed the longer it continues. This is consistent with the results of Atkinson and Sonley (2000).

The difference between our intensity relation and those published previously is interesting to consider. Taken at face value, Figure 6 appears to be consistent with previous results suggesting that a higher level of high-frequency energy from intraplate earthquakes will be more damaging to many kinds 


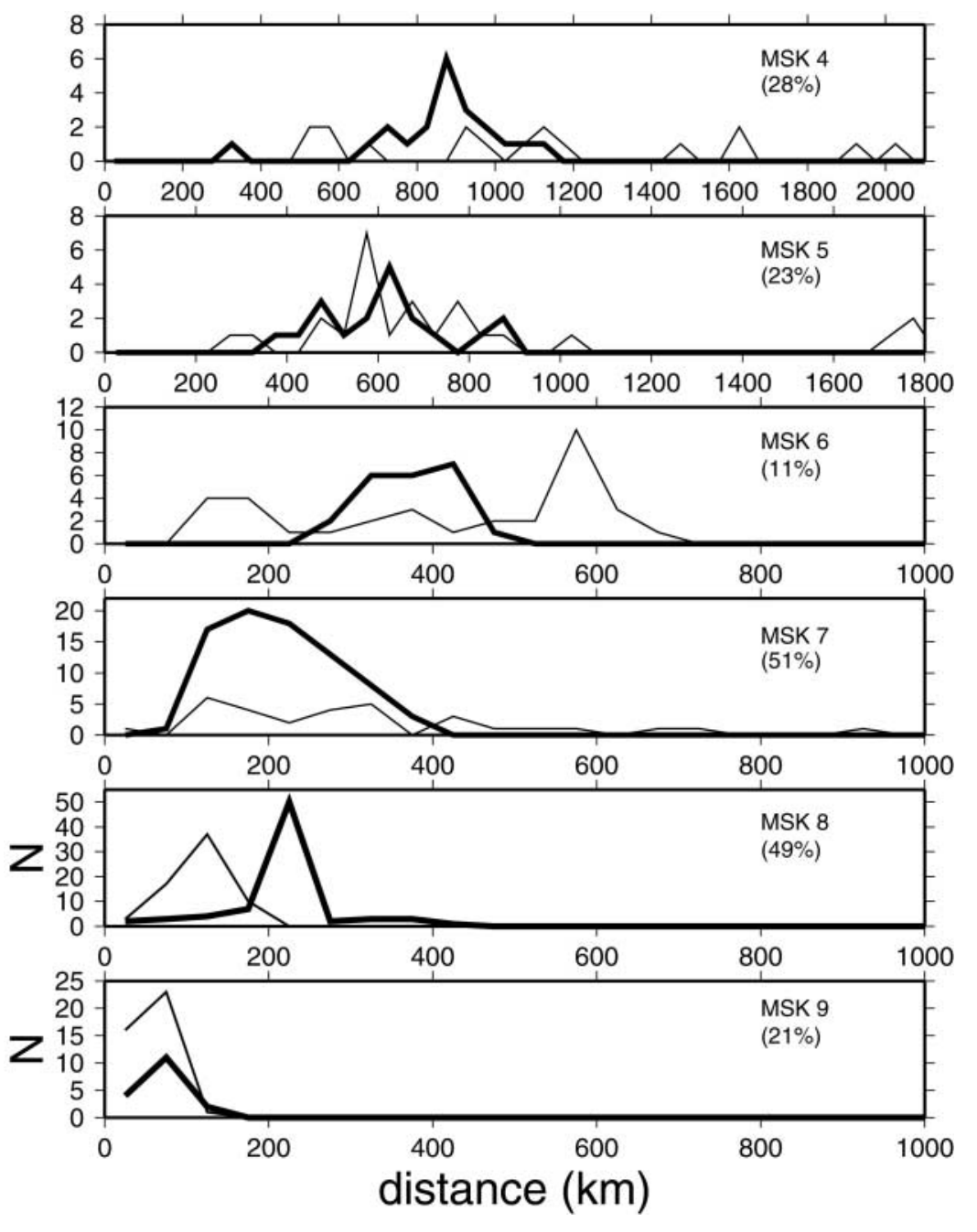

Figure 3. The distribution of intensity levels 4-9 as a function of epicentral distance for both GSI03 (dark lines) and MEDIA02 (light lines). The fractional media bias, MBS, for each intensity level is shown in each panel.

of structures-especially smaller ones-than the shaking from comparable earthquakes in interplate regions with a comparable PGA (e.g., Greig and Atkinson, 1993). For example, Figure 6 indicates that a PGA of $10 \% g$ corresponds to intensities VI in California and VII in India. One might also speculate that, although intensity scales explicitly consider building vulnerability, the Bhuj intensities might still be biased toward high values because the high vulnerability of structures was not fully taken into account.

The results illustrated in Figure 5b, however, suggest a different interpretation: that the relationship between intensity and magnitude depends on the magnitude of the earthquake and, correspondingly, the distances over which an event is felt. This conclusion is, in fact, implicit in equation (2). When distance and magnitude are taken into account, as in the relationship developed by Atkinson and Sonley (2000), then at least at distances of 0-300 km, the relationship between MMI and PGA is in fact comparable in intraplate and interplate regions. This further suggests that our simple MMI versus PGA relationship for the Bhuj earthquake (Fig. 6) is only valid for earthquakes of comparable magnitude. The results developed for the Bhuj earthquake, how-

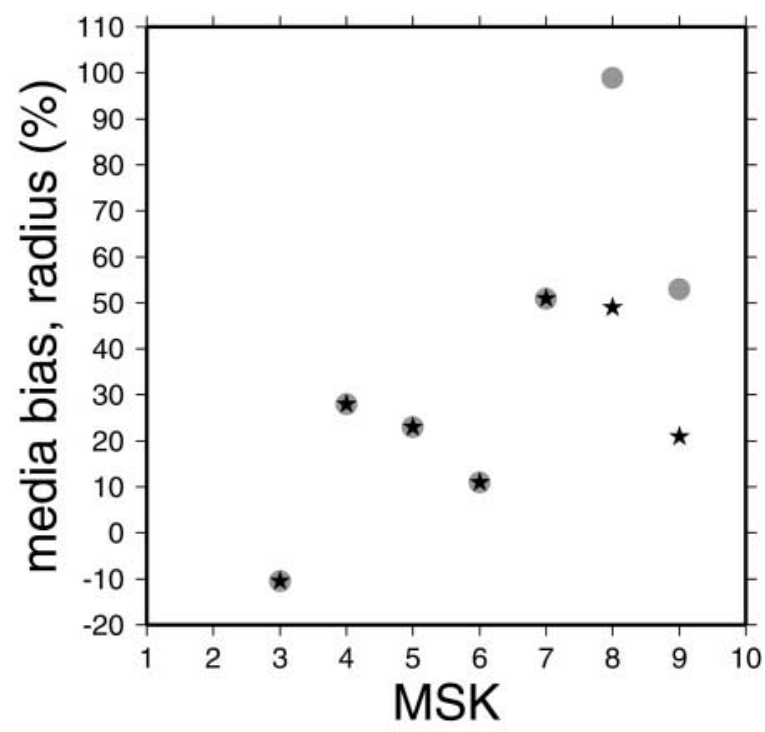

Figure 4. The fractional media bias, MBS, as a function of intensity level. Gray circles indicate results using MEDIA02 intensity values that were determined based on liquefaction observations alone; black stars indicate the results when these values are excluded. 
(a)

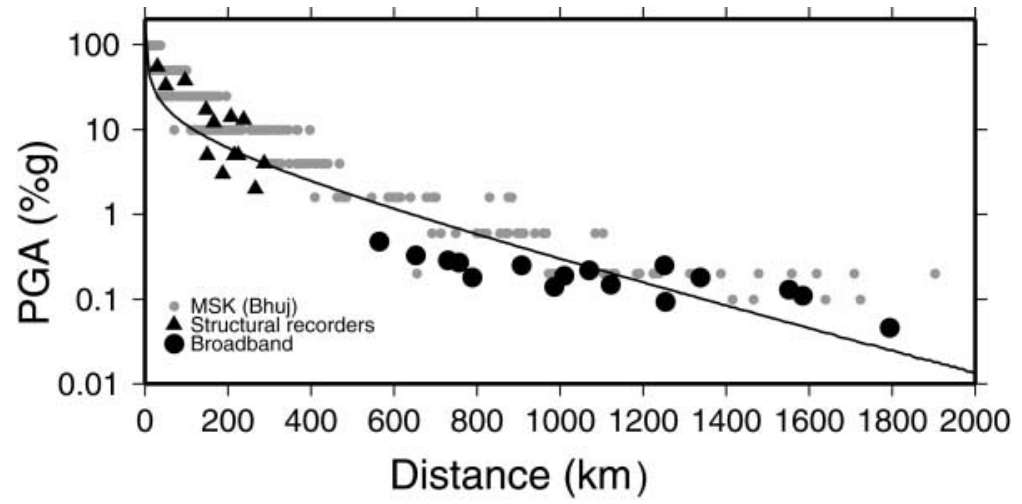

(b)

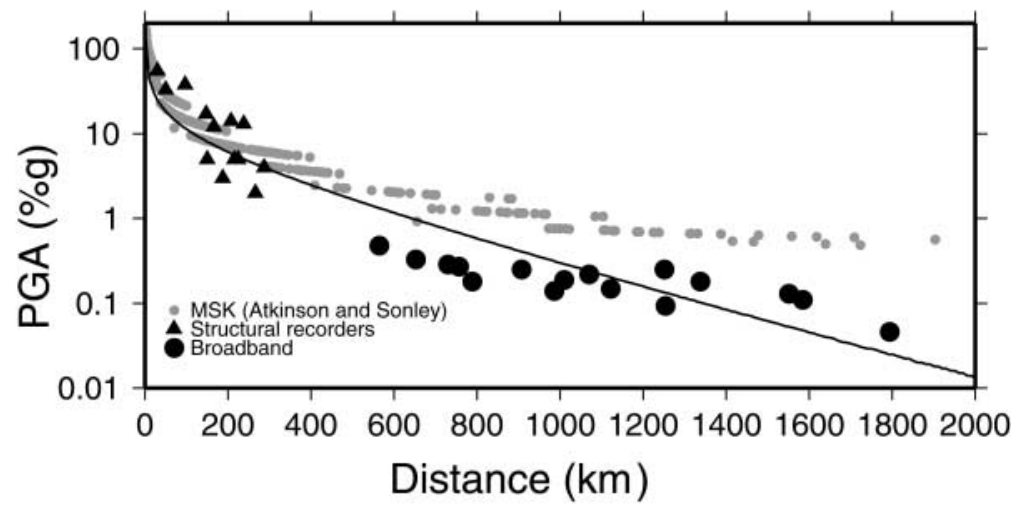

(c)

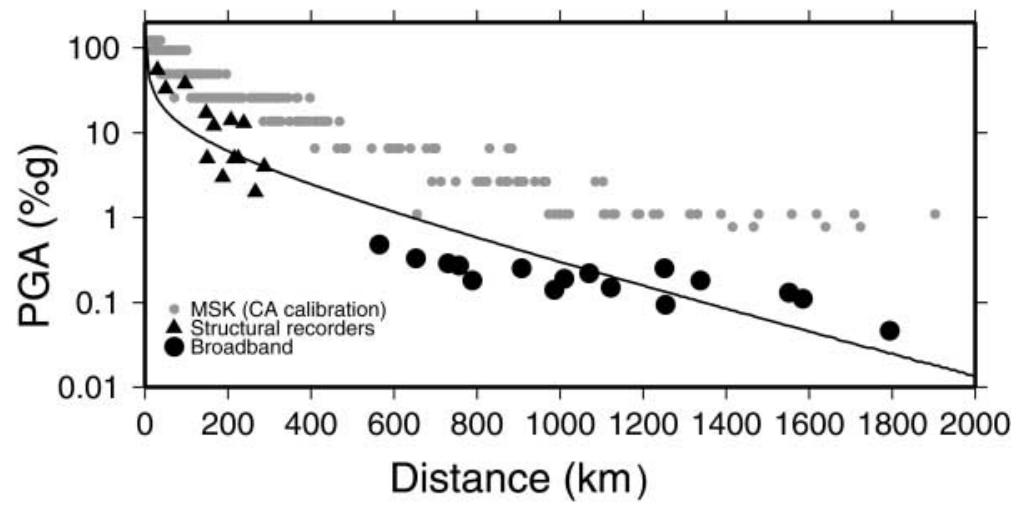

Figure 5. (a) Peak acceleration values (\%g) estimated from structural response recorders (triangles; Chandra et al., 2002), regional broadband seismometers (large black circles; Singh et al., 2003), and from GSI03 intensity values using the intensity-PGA relation determined in this study (small gray circles). (b) Same as (a), but PGA values estimated using the relationship of Atkinson and Sonley (2000). (c) Same as (a) but using the intensityPGA relation determined for California. ever, do provide a basis for interpreting the intensity values of historic earthquakes of comparable size.

\section{Conclusions}

The 2001 Bhuj, India, earthquake is a key event for understanding not only earthquake hazard in India but also hazard in similar geologic/tectonic settings worldwide. A quantification of the macroseismic effects of the earthquake is critical, yet it is complicated by the myriad difficulties associated with assignment and interpretation of intensity values. The availability of two extensive, independent intensity surveys for the Bhuj earthquake provides the basis for a detailed comparison between the methods traditionally used to determine intensities: direct surveys and evaluation of documentary (e.g., written) accounts. This comparison yields several interesting insights into the nature of the socalled media bias - the tendency of untrained observers to focus on the most dramatic, rather than the representative, effects in their written accounts. Although seismologists recognize the importance of assigning intensities based on representative rather than pathological effects, any interpretations will inevitably be biased if available documentary accounts are themselves biased. We conclude that this bias can be significant, and is most severe at the strongest shaking levels. The bias is much lower at the lowest-intensity levels; the intensity level of $\mathrm{V}$ is also found to be a relatively stable indicator, although it can be biased by outliers. Our results suggest that care is needed in using modern calibration 


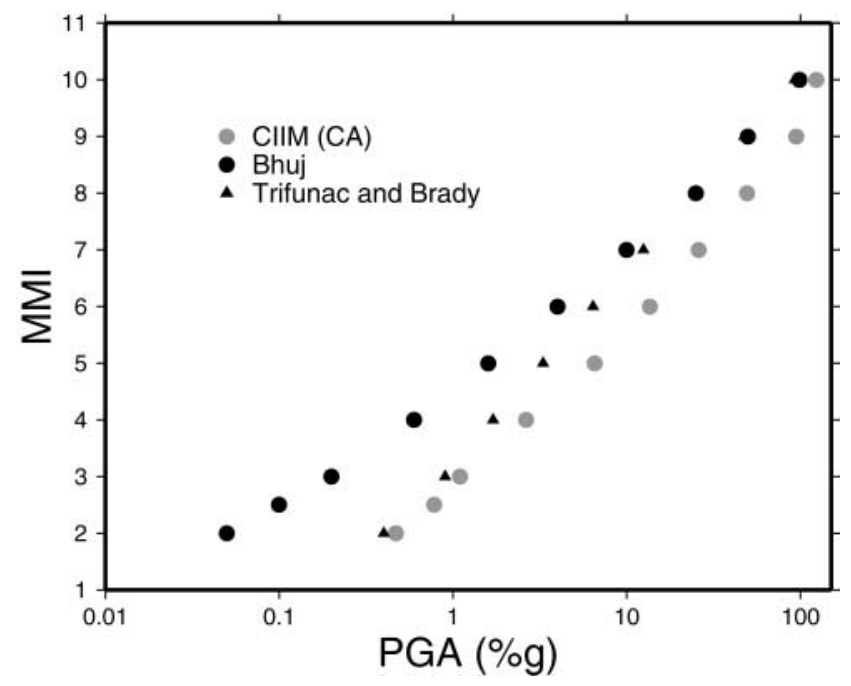

Figure 6. Intensity versus PGA $(\% g)$ determined by Trifunac and Brady (1975) (triangles), Wald et al. (1999) (gray circles), and this study (black circles).

events to assess the magnitudes of historic earthquakes, for which only documentary data are available.

\section{Acknowledgments}

We thank Karen Felzer and Erdal Safak for constructive criticisms and feedback, and an anonymous reviewer for comments that improved the manuscript.

\section{References}

Ambraseys, N., and R. J. Douglas (2004). Magnitude calibration of northern Indian earthquakes, Geophys. J. Int. 159, 165-206.

Ambraseys, N. N., and C. P. Melville (1982). A History of Persian Earthquakes, Cambridge University Press, New York.

Antolik, M., and D. S. Dreger (2003). Rupture process of the 26 January $2001 \mathrm{Mw}$ 7.6 Bhuj, India, earthquake from teleseismic broadband data, Bull. Seism. Soc. Am. 93, 1235-1248.

Atkinson, G. M., and E. Sonley (2000). Empirical relationships between modified Mercalli intensity and response spectrum, Bull. Seism. Soc. Am. 90, 537-544.

Bakun, W., and M. Hopper (2004). Magnitudes and locations of the 18111812 New Madrid, Missouri, and the 1886 Charleston, South Carolina, earthquakes, Bull. Seism. Soc. Am. 94, 64-75.

Bendick, R., R. Bilham, E. Fielding, V. Gaur, S. E. Hough, G. Kier, M. N. Kulkarni, S. Martin, K. Mueller, and M. Mukul (2001). The January 26, 2001 Bhuj, India earthquake, Seism. Res. Lett. 72, 328-335.

Chandra, B., S. K. Thakkar, S. Basu, A. Kumar, M. Shrikhande, J. Das, P. Agarwal, and M. K. Bansal (2002). Strong motion records, Earthquake Spectra 18 (suppl. A), 53-66.

Greig, G., and G. M. Atkinson (1993). Damage potential of eastern North American earthquakes, Seism. Res. Lett. 64, 119-137.
Grunthal, G. (Editor) (1998). European Macroseismic Scale 1998, Vol. 15, ESC, Cahiers du Centre European de Geodynamique et de Sismologie, Luxemburg, 79 pp.

Hanks, T. C., and A. Johnston (1992). Common features of the excitation and propagation of strong ground motion for North American earthquakes, Bull. Seism. Soc. Am. 82, 1-23.

Hough, S. E., and A. Elliott (2004). Revisiting the 23 February 1892 Laguna Salada earthquake, Bull. Seism. Soc. Am. 94, 1571-1578.

Hough, S. E., S. Martin, R. Bilham, and G. M. Atkinson (2002). The 26 January 2001 M7.6 Bhuj, India earthquake: observed and predicted ground motions, Bull. Seism. Soc. Am. 92, 2061-2079.

Iyengar, R. N., and S.T.G.R. Kanth (2006). Strong ground motion estimation during the Kutch, India earthquake, Pure Appl. Geophys. 163, 153-173.

Mallet, R. (1862). Great Neapolitan earthquake of 1857, in The First Principles of Observational Seismology, Vol. 1, Chapman and Hall, London.

Musson, R.M.W. (1998). The Barrow-in-Furness earthquake of 15 February 1865: liquefaction from a very small magnitude event, Pure Appl. Geophys. 152, 733-745.

Nuttli, O. W. (1973). The Mississippi Valley earthquakes of 1811 and 1812: intensities, ground motion, and magnitude, Bull. Seism. Soc. Am. 63, $227-248$.

Oldham, R. D. (1899). Report on the great earthquake of 12th June 1897 (incl. the reports by Bose, P., G. Grimes, H. Hayden, T. LaTouche, and E. Vredenburg), Mem. Geol. Surv. India 29, 1379.

Pande, P. (2003). Kutch (Bhuj) earthquake of 26 January 2001, Geological Survey of India Special Publication no. 76.

Singh, S. K., B. K. Bansal, S. N. Battacharya, J. Pacheco, R. Dattatrayam, M. Ordaz, G. Suresh, A. Kumal, and S. E. Hough (2003). Estimation of ground motion from Bhuj (26 January, 2001; Mw = 7.6) and from future earthquakes in India, Bull. Seism. Soc. Am. 93, 353-370.

Stover, C. W., and J. L. Coffman (1993). Seismicity of the United States, 1568-1989 (revised), U.S. Geol. Surv. Profess. Pap. 1527.

Strand, C. L. (1980). Pre-1900 earthquakes of Baja California and San Diego County, Master's Thesis, San Diego State University, San Diego, California, $320 \mathrm{pp}$.

Trifunac, M. D., and A. G. Brady (1975). On the correlation of seismic intensity scales with peaks of recorded ground motion, Bull. Seism. Soc. Am. 65, 139-162.

Wald, D. J., V. Quitoriano, T. H. Heaton, and H. Kanamori (1999). Relationships between peak ground acceleration, peak ground velocity, and modified Mercalli intensity in California, Earthquake Spectra 15, $557-564$.

Wessel, P., and W.H.F. Smith (1991). Free software helps map and display data, EOS Trans. AGU 72, 441, 445.

U.S. Geological Survey

Pasadena, California 91106

(S.E.H.)

Geological Survey of India

Lucknow, Uttar Pradesh

India

(P.P.) 